\title{
When Social Support Fits into your Luggage: Online Support Seeking and its Effects on the Traditional Study Abroad Experience
}

\section{Jude P. Mikal}

University of California, Santa Barbara

\section{Introduction}

The theories of intercultural adjustment that have dominated research on acculturative stress and culture shock are based on notions of transition that have failed to keep pace with changing media technology. Intercultural adjustment theorists like Oberg, Lysgaard and Adler were operating in a time when lengthy, cost prohibitive modes of communication were the norm, and logistical considerations meant the severing of all but the most intimate of ties while overseas. Forty years post hence, the information age has demolished the communication barriers that were the cornerstone of early theories of initial target culture contact. For modern students communication is free and frequent as university students continuously maintain dual existences on-, and off-line. Where physical whereabouts play an integral role in the first, the second is maintained irrespective of physical boundaries. Thus where study abroad represents a similar displacement for students today as it did forty years ago; modern students maintain an online persona that likely changes the degree to which physical displacement is appraised as a potential stressor.

Dubbed the Net Generation (Leung, 2007), modern university students have grown up not only with advanced communication technologies at their disposal, but using such technologies to both maintain and create social networks of support. In a study abroad context, the maintenance of dual on- and offline personas provides students with the opportunity to demolish communication barriers with the home culture created by geographic distance. Conversely, online communication may help bring down communication barriers created by linguistic and cultural differences, providing students with exciting opportunities for face-to-face social interaction with host nationals. Yet, very little is known about how students are using the Internet in the development or maintenance of social support networks during study abroad. The goal of the present research project is to understand how Internet 
mediated support complements, supplements or supplants traditional support seeking and how online support seeking leads to changes in the traditional study abroad experience. In the next section of this study I will present relevant literature on the subjects of acculturative stress, social coping, and Internet mediated social support in order to ground the research question and study findings.

\section{Relevant Literature}

Normative models of acculturative stress generally rely on two common assumptions: (1) that international migration is characterized by heightened stress levels; and (2) that the key to coping with such stress is social interaction. U-curve models, conceived in the mid-1950s suggested a painful initial adjustment to a new culture that occurred in 3-5 steps, roughly introduction, followed by crisis, and later, recovery. The catalyst for movement between the stages was increased engagement with the target culture (Lysgaard, 1955; Oberg, 1960; Adler, 1975). While such prescriptive models have been debunked both empirically and theoretically (e.g. Church, 1982; McKinlay, et al., 1996). still, more modern intercultural adjustment theories like acculturation attitudes / acculturation strategies conceived by Berry (1991), and developed by Ward and Kennedy (1994) rely on similar assumptions. The model attempts to predict differential stress levels abroad, by looking at attitudes towards home culture maintenance vs. desire for integration - measured, at least in part, by peer network composition.

Taking these two assumptions for granted, literature on social coping offers insight into the mechanisms through social support can act to alleviate stress. Literature on social coping suggests that support may take one of three forms: (1) instrumental support refers to the provision of goods or services used to cope with a stressor; (2) informational support refers to the transfer of relevant information for dealing with a stressor; and finally (3) socio-emotional support refers to the feelings of acceptance and togetherness that come from social interaction (Cohen, S., \& Wills, T.A., 1985). Other theorists have noted that individuals may find support simply through their participation in a broader social network - and research has shown that this degree of "embedded support" also shows a positive correlation with psychological wellbeing (Cohen, S., \& Wills, T.A., 1985; Thoits, P.A., 1986).

Studies on computer-mediated communication (CMC) have shown the Internet to be an effective tool in the communication of both socio-emotional and informational support. Evidence in such studies has failed to demonstrate a link between Internet communication and the transmission of instrumental support, and to date, no study has examined the Internet as a possible social 
context through which to derive embedded support. Conversely, research on $\mathrm{CMC}$ and Internet mediated social support demonstrates that the Internet is not only a useful tool in facilitating communication over large distances (Dimmick, et al., 2000), but that there are a number of relative advantages to social support received online. For example, research has shown the Internet to be an effective tool for support seeking among individuals with difficulties with face-to-face communication, or for those who find face-to-face communication less rewarding. Thus far, such studies have been concerned primarily with mental handicaps, such as Asberger's Syndrome and Autism (e.g. Burke, Kraut \& Williams, 2010), and stigmatized conditions, such as infertility (e.g. Malik \& Coulsin, 2008); however, the present study extends empirical analysis to include study abroad participants given their status as marginalized linguistic and cultural minorities who experience language and cultural barriers to communication.

Early studies on Internet communication have suggested that while the Internet increases the quantity of social interactions, it does so at the expense of quality (Kraut, et al., 1998; Baym, N.K., 2004), but notions of such quality / quantity tradeoffs are becoming increasingly antiquated. No longer is the assumption that friendships are formed or maintained exclusively on- or offline (Subrahmanyam, K., 2008). Research on social networking sites like Facebook which has exploded to over 550 million members worldwide (www. facebook.com), has demonstrated that such sites facilitate the maintenance of and reconnection with socially supportive peer networks, and recent work (Raacke \& Bonds-Raacke (2008)) has demonstrated that the site is a useful tool in the construction of new friendships. Researchers are further suggesting that relationships developed online may be more meaningful given that they are generally based on common interests, and a common life-situation, rather than simple geographic proximity.

Despite growing recognition of the advantages of Internet mediated social support, concerns remain. While there is little agreement among researchers as to the relationship between online and offline social interaction, early empirical studies indicated that increased social interaction online is correlated with decreased face-to-face interactions (Papacharissi, 2000; Putnam, 2000; Kraut, et al., 1998), though more recent studies are finding the converse to be true (Hampton, 2003; Robinson, et al., 2000, McKenna, 2002). Researchers have found that increased convenience in online transactions means that individuals are no longer required to leave their homes for minor errands (such as shopping) leading to decreased daily social interaction, and higher risk of depression (Kraut, et al., 1998). Further, while the Internet allows for the construction of support communities across communication 
boundaries, studies have found that in the absence of emotional or tonal cues, misunderstandings are more likely to occur. In a comparative study of group work conducted on and offline, researchers found that groups who conducted their work primarily online were less cohesive and less satisfied with group work outcomes (McKenna, 2002). Finally, studies have demonstrated that increased online activity is associated with decreased academic performance, less social involvement, and increased loneliness and depression (Shaw, L.H., \& Grant, L.M., 2002).

This present paper contributes to a more complete understanding of the role of the Internet in the formation and maintenance of social support networks during study abroad. Specifically this research represents a first look at how the Internet serves to overcome communication barriers arising from linguistic and cultural differences encountered abroad. During study abroad, students may look to the Internet to help break down communication barriers and form friendships with members of the target culture, or conversely, to help them feel closer to socially supportive relationships back in the home culture. The paper also examines how increased access to both types of social support online changes the traditional study abroad experience, both in terms of students' intercultural adjustment, as well as in the proportion of students' social support networks made up of host nationals, co-nationals living abroad, and co-nationals living in the home country. Finally, the paper represents the beginning of a discussion of theoretical models of intercultural adjustment, and how such models ought to be adjusted to account for dramatic increases in communication technologies.

\section{Methodology}

Data was gathered in four two-hour focus groups held in Northern Germany in 2009. Focus groups consisted of four topics: (1) the transition abroad, (2) peer network composition, (3) advantages of maintianed Internet use during study abroad, and (4) disadvantages of maintained Internet use. The protocol was semi-structured, and students were allowed and encouraged to deviate from prescribed topics, but a routine of approximately 30 minutes per discussion topic was adhered to. Focus groups were scheduled every two weeks, allowing time to transcribe each session by hand, code each session and modify focus group protocol for the subsequent session. Once all four focus groups were complete, a thorough coding was conducted using a combination of bottom-up and top-down techniques.

Focus group participants were graduate and undergraduate students studying abroad in Germany. Due to theoretical considerations, respondents were required to be American, to be affiliated with a university and to be 
abroad for more than 3 weeks. In all, 21 students participated in the two-hour focus groups. Programs represented ranged from traditional, full-immersion, year long programs - to independent research in an English-speaking institute under the guidance of a German professor. Participants ranged in age from 20 to 32.18 participants were Euro-Caucasian, while 3 were East Asian. Of the 21 participants, 10 were graduate students, 11 were undergraduates; 14 were social science majors, 5 were in physical sciences, 1 student was studying architecture and 1 was studying Humanities. All 21 students had regular Internet access through a laptop, university housing or place of employment.

\section{Results}

Results indicate that students are accessing socio-emotional, informational and embedded support online, and will be organized into the following three themes: (1) Internet as Transitional Device: Early normative models of acculturative stress suggest an initial decline in psychological wellbeing, due to disorientation. Students are smoothing the transition abroad by using online technology to supplement socio-emotional support through home support networks. (2) Internet as Cultural Inlet: Data suggests that students are supplanting face-to-face Informational support with Internet mediated support in order to create opportunities for interaction in the target culture, and to facilitate rapid establishment of daily routines in the host culture. (3) Internet as Placeholder in the Home Culture: Students abroad look at their social support networks back home as "paused". Students use the Internet to provide socio-emotional support, thus reminding friends and family of students' secured place within those networks. Finally, results indicate that despite increased access to support, students are still evidencing heightened stress levels. These findings are discussed below.

\section{Transitional device}

A recurrent theme that emerged among focus group participants was the use of Internet technology to provide continuity during the transition abroad. Two respondents in two different focus groups reported that the Internet served as a "lifeline" to social support networks in the home country. Evidence suggests that the Internet serves two specific transitional functions: (1) it smoothes the transition abroad by providing continuous access to social support networks back in the country of origin, and (2) provides identity affirming embedded support through participation in a broader social network.

Students of the Net Generation are accustomed to the spillover of personal relationships into cyberspace, and conversely, of cyber relationships into real space. According to one respondent, relationships can no longer be conceived 
of as either maintained on or offline, since most relationships are maintained through multiple media.

We've had technology growing up. Through high school and now college, I've had a cell phone, a computer and the Internet, so most of my friendships are still established around those forms of technology (H4: Holly, graduate student, research assistant in an international research institute, abroad for five months).

The Internet does not represent an abstracted, impersonal medium of communication, or even an extension of personal relationships. Rather friendships are formed and maintained through multiple media to the extent that the online persona is symbiotic with the offline persona.

With friendships that straddle both real- and cyber-space, it is logical that when face-to-face contact is no longer possible given large geographic distance, students comfortably rely on computer-mediated communication in order to maintain socially supportive relationships. According to one respondent, he is used to maintaining relationships over the Internet, since he formed the habit when he moved to New York from Colorado to attend university.

For me going abroad just so closely parallels university life. I live in Colorado and go to school in New York, so I switch [between locations] so often and for months at a time. This is just like being in New York for a few months. The only difference is that I'm not with the people I would normally interact with in New York (A3: Adam, undergraduate, taking courses in a non-immersion program, abroad for one semester).

Study abroad simply represents a third place - neither home nor university. Rather than maintaining a single group of friends exclusively online, students must maintain two groups of friends online, while negotiating a bilateral (on and offline) entry into a third culture.

All students reported maintaining regular contact with members of the home culture with the primarily goal of obtaining socio-emotional support. Two respondents from focus group four reported talking to their mothers daily,

I talked to my mom when I was in college almost every day, and I still do it here. Even if it's just for like two or three minutes so say, "Have a great day." It makes me feel better when I hear from her, and she feels better when she hears from me. We're just so close (H4: Holly).

Others were likely to maintain daily contact with the home culture, when they were involved in significant romantic relationships. According to another respondent the Internet smoothed the transition from daily contact with her romantic partner, to intermittent contact complicated by a nine-hour time difference. 
At the beginning, I was up until five o'clock in the morning every night [talking online to my boyfriend]. If I didn't talk to him everyday, I was like, "Oh my God, what is he doing? He doesn't love me anymore!" I mean he felt the same way, but it was especially hard - especially while I was transitioning here (K4: Karen, undergraduate, taking courses in a non-immersion environment, abroad for one semester).

The respondent further reported staying online for several hours at a time, hoping to be online when her partner logged on to the Internet in the United States, so that the two could make contact.

Students were also likely to maintain contact with members of their peer groups through multiple interfaces. All 21 respondents had accounts on social networking sites through which they maintained regular contact with friends and family, providing pictures and daily updates on everything from outings, to mood, to dinner. According to a respondent in focus group one, her parents continue to keep track of her through her daily "tweeting" of her meals.

I went out on Friday night and I did not [record my dinner on] Twitter.

So my dad checks my Twitter [account], and when he didn't see my dinner, he was very concerned. So my mom emails me, and then my sister posts on my wall on Facebook saying, "Why haven't you Tweeted your dinner?" (Sa1: Samantha, graduate student, taking courses in an international research institute, abroad for one month)

Through social networking sites, students remain a virtual presence among social support networks and are able to maintain a certain base-level support while abroad. Before leaving for a 10-day trip another respondent reported emailing friends, and updating her Facebook status to reflect that she would be incommunicado in the days to come. Thus, the respondent indicates the need to deactivate base-level support during her absence, for fear that her silence might be interpreted as a need for support - as in the Samantha quote, above.

The concerns expressed by Samantha's father, in the absence of a Twitter "status update" reflect another continuity provided by the Internet through the transition abroad. Students reported generally stable Internet use habits from which they derived support. Most students reported that they had an Internet routine for their day. While some students simply checked email in the morning and at night, others had more detailed routines,

I eat my yogurt and muesli, and while I do it I look on the Internet, check my Gmail, and check my university email. Then I check Facebook and Twitter. I'll potentially check two blogs of these girls I sort of know, and maybe the New York Times. If there's still something to do, maybe I'll follow some links on Twitter, but that's sort of the 
morning [portion of the routine]. When I get home [from work] I do the Facebook / Twitter check again, and I'll continue that throughout the night because people are updating. At some point in the evening I'll talk to my boyfriend on Skype, and I'll watch television online, like the Daily Show, or listen to a podcast. Yeah - that's my typical Internet day (Sa1: Samantha).

It was not uncommon for students to report such ritualized Internet use patterns. Even several students without such detailed routines reported that they were likely to keep their computers logged onto the Internet, with tabs open to gaming sites, email and social networking sites depending on their interests.

\section{Cultural inlets and cultural consumerism}

Along with Internet use providing continued access to online networks of support, as discussed in the section on Transitional Objects above, the data suggest that students are interested in a quick and efficient establishment of daily routines once abroad - and are using the Internet as the means to achieve this goal. From the moment students enter the new culture they are demonstrating agency in their cultural and physical orientations. No longer must students wander lost through a city armed with a map and a rudimentary understanding of the target language. Students are locating products and areas of interest from the safety of their residence as of the first day. "My first morning I Googled where to find coffee. I Googled something like, "coffee in [my city]" and found a place that was close to my apartment (Sa1: Samantha)." Once students locate the item or area of interest they are using mapping programs such as Google Maps to plan their route. In fact, virtually all students reported using a mapping program to orient themselves with relation to their surroundings, with several reporting having used a mapping program to obtain directions to the focus group location.

From orienting themselves during the initial transition abroad, to the establishment of daily routine within the host culture, focus group data shows that students are creating their lives abroad independently and without much help from (or contact with) the target culture. Focus group three consisted of four students participating in a study abroad program that required no prior knowledge of German. For these students the prospect of setting up a bank account without access to bank information online in English seemed nearly impossible.

The idea [of setting up a bank account] terrifies me. If I wanted to set up an account with a German bank I wouldn't know what they were saying to me. I would definitely take someone with me who knows 
better German (Me3: Melissa, undergraduate, taking courses in a nonimmersion program, abroad for one semester).

Melissa, like others of the Net Generation, believes that, "it's better to have more information than less." As a result, Melissa and other Net Generation students are opting out of cross-cultural encounters where access to information may be slowed or limited due to communication difficulties. Results indicate that students are using the Internet to bypass many potential cross-cultural interactions in favor of a more rapid establishment of daily routine. No longer are students forced to browse classified listings, phone for availability, and set up viewings in order to find an apartment. Rather, students are able to browse apartment listings with photos on the Internet, and initiate contact through low risk media such as email. Public transit fares, tickets and special offers can all be located online, often in English, or translated with the help of online translation programs. Further, no longer are students sitting with travel agents to book train and airline tickets, but rather booking, and often even checking in, online.

To students, integration without exercising linguistic and cultural competencies comes down to a question of efficiency. Students no longer view themselves as cultural anthropologists exploring new and undiscovered cultures, but simply following the path set by those before them. In the industry of study abroad, the students have become cultural consumers. Melissa offers the following illustrative anecdote,

We decided the other way to go to Victoria Park, but we'd never been there before, so we just Google Mapped how we would ride our bikes there. Now technically you could make the argument that if we hadn't done that, we may have discovered some undiscovered place along the way and had this wonderful adventure but you know, we got there and managed to find an amazing place to have lunch. Because we're using our time more efficiently in getting to places, we can know those places and those areas better (Me3: Melissa).

Traveling with a destination in mind, students are no longer venturing off the beaten path. "Knowing" a culture is less an exploration than the compilation and completion of a checklist of cultural artifacts. For students spending a limited time abroad, agency and determination are essential components of effective and efficient consumption of German culture.

Cultural consumption should not imply that students are not learning, or that the Internet is not an effective tool for the establishment of daily routines and creation of cultural inlets. For while integration through exploration, virtually by definition, involves a certain number of missteps; integration 
through Internet allows students to circumvent those missteps which can be not only embarrassing, but financially costly. One respondent gives the following example,

The thing about the Internet is that it saves you a lot of embarrassment. I wanted to go fishing while I was here, and I was looking up tackle shops, and I found out in trying to do that that it takes forty or fifty hours of fishing training to get a license here in Berlin. If I had gone fishing and gotten caught by police they would have fined me for poaching, for trespassing, for fishing without a license and it would have cost me close to a thousand Euro. I mean I could have learned that on my own, but I prefer to learn that from the Internet (G3: Grant).

It is important to note that while cultural misunderstandings are endemic in cultural exploration, they are the "means" which have long been justified by the "ends" of cultural and language learning. In many ways, the Internet allows students to acquire and apply cultural lessons through less abrasive means.

Not only may the Internet prevent cultural missteps, but using the Internet in the establishment of daily routines may reflect an understanding of a worldwide "Internet culture." While only a few years ago Americans comprised $70 \%$ of all Internet users, that number plummeted to $30 \%$ in 2007 (Lievrouw, L.A., 2000 cited in Raacke and Bonds-Raacke, 2008). As a result, avoiding face-to-face interactions in favor of online information seeking may not be reflecting students' ethnocentricity, so much as reflecting a global trend toward modernity. A respondent from focus group four offers the following justification of purchasing tickets online:

These exercises in talking with a ticket agent are antiquated. There are machines now - like fast pass tolls in the U.S. - and those personal interactions go away over time. They may be good practice and exposure to the culture in a sense, but if it goes away and won't be a part of the culture anymore, what's the point? (T4: Tom, graduate student, research assistant at an international research institute, abroad for one year)

Students recognize that like America, German society is moving toward automation of certain services. Purchasing tickets online does not constitute cultural avoidance - as young Germans are also prone to purchasing tickets online. If anything, synthetic encounters with German culture of the past are no longer sufficient exercises in language and cultural learning.

Rather than seeking out cultural and language learning opportunities through everyday interactions such as ticket purchases and apartment searches, students are seeking out more substantive interactions with the target culture 
based on more than simple casual contact. Data demonstrate that students are using the Internet to make connections through cultural activities. All students reported using the Internet to locate cultural events such as art exhibitions and political speeches. Tom, quoted above, recommended using the Internet to look for special theme nights at local dance clubs, while another respondent from focus group one reported that, although she speaks no German, she was likely to purchase symphony orchestra or ballet tickets from the local theatre online. Nicholas, a former professional athlete reported that he was able to use the Internet to connect with the target culture by finding a sports league in which to participate. He reports,

Finding this soccer team was probably the best thing for my German, probably the best thing for seeing other parts of the state, for meeting other German people and for getting a little bit more entrenched in the culture (N1: Nicholas, graduate student, research assistant at an international research institute, abroad for one year).

Finding a soccer league allowed Nicholas to create a network of friends who, at the time of the interview, constituted a significant portion of his face-toface social support network. A few students also reported using the Internet to extend party invitations to host nationals. Though these interactions often did not result in the creation of new friendships, they generally resulted in exposure to an element of the German culture - and the possibility for interaction created by the Internet. Furthermore, the Internet allows for access to logistical information such as clubs, events, and exhibitions that may be prohibitively complicated in the target language, such that students can spend more time creating possible engagements with the culture, and less time in fruitless searches for ways to engage.

Focus group data also showed that social connections online can translate into increased face-to-face interaction. Social networking sites, particularly country-specific sites, provide opportunities to connect with others within the community. Kimberly used Facebook to strengthen a friendship with another American she had met several times at a party:

I was friends with this guy on Facebook because we just kept randomly meeting at parties, but I didn't really spent that much time talking to him. Anyway, so he wrote something on his wall - I think it was his 'top five favorite bands' or whatever, and they happened to be exactly what I like, so I was all, "Oh my God that's so awesome!” Then he ended up signing on right there and we just kept talking and talking and now we're going to meet somewhere next week - we were just like, "Wow! We should hang out! We have so much in common!" (K2: Kimberly, undergraduate student, taking courses in a full-immersion 
program, abroad for one year)

Others reported feeling as though friendships had been strengthened over the Internet. Adam reports meeting people at a party, and feeling as though requesting a subsequent meeting might be overly forward. Facebook allows him to take the first step, "I think it's because they're kind of afraid to initiate another physical [face-to-face] contact or communication at first." (A2: Adam) And Kimberly continues, "And it's easier to invite twenty people to a barbecue and include someone you just met, than to call them up and be like, "Hi! Remember me from last night?" (K2: Kimberly) The Internet provides an effective method of communication for those for whom face-toface interaction might seem too forward. Students do not risk rejection, and are able to expand social circles more easily.

\section{Internet use and maintenance of ties back home}

The idea of a life "on pause" back in the home culture became a theme in each of the four focus groups. Data suggest that the Internet enables students to continue attending to responsibilities within the home culture while living abroad. This continued attention to social and professional obligations back in the United States serves two functions. First, the ability to attend to obligations makes study abroad available to many students whose impacted schedules may have prevented them from studying abroad in the past. Second, continued attention to social and professional obligations softens the transition back into the United States by securing positions in important personal and professional networks.

Data indicated that students are aware of the short-term nature of their study abroad experiences and as a result were unlikely at the start of their sojourn to give up coveted positions in university sports or clubs. Grant, from focus group three, continued running a university club in the United States during his semester abroad, and talked about how the Internet has allowed him to maintain his role as an active member,

I run a club at NYU and it hasn't been hard at all. I've actually

participated in meetings and stuff through the Internet and I've kept in contact - at least with the active members - on a day-to-day basis to see what they're doing (G3: Grant).

Students, like Grant are likely to spend their time abroad living in two cultures - simultaneously participating in clubs, maintaining friendships and fulfilling professional obligations within the home country, while physically living abroad. 
Professional obligations were central concerns for three focus group respondents. Two respondents reported that fulfillment of their degree requirements required the completion of a summer internship. Students were required to submit the applications for these positions in late April, but they wouldn't be returning to the United States until late May. While some businesses were reluctant, or refused to accept internship applications submitted online, the two students were using the Internet to submit applications to other technologically well-equipped firms. Similarly, Nicholas from focus group one was applying to graduate school, while completing an internship with a research institute in Germany. Applications were due in December, for the coming fall semester.

Students also reported using the Internet to secure their position in social support networks back home by both seeking and providing support online. One respondent who had lived abroad in several countries reported that no longer does moving necessitate the abandoning of one social support network and the formation of another. Rather, social support network formation becomes an additive process as friendship networks become more global. Nevertheless, according to one respondent, maintenance of home culture ties involves a certain effort. For Robyn increasing her "presence" on Facebook was a way of asserting her position in social support networks, and not being left behind. "I would say my Facebook use is more productive in the way that I'm making myself a little more known. Like, 'Hey, nice picture.”' It's like saying, 'Hey, I'm still here!'” (R1: Robyn, graduate student, taking courses in an international research institute, abroad for two months) According to Robyn, this represents a change from her past Facebook behavior due to her physical absence. Erin clarified the need for this online presence, saying,

I couldn't imagine being abroad without the Internet. If you think about it even when I get back there's going to be this ten-month gap where I don't connect with my friends because they've moved on. They're ten months ahead, and I'm coming back to a life that I've put on hold. If I didn't have the Internet I would be totally behind. It would make reintegrating back into American culture so much harder (E1: Erin, undergraduate student, taking courses in a full immersion program, abroad for one year).

Kimberly, from focus group two, also echoed the sentiment, saying that without the Internet she would be required to abandon social support networks for a full ten months causing her to be left behind.

Due to the temporary nature of study abroad programs, students are likely to be stressed about obligations they have in their home country once their 
time abroad is complete. As universities grapple with how to reconcile study abroad, with demanding obligations in students' home universities, students appear to be taking matters into their own hands by attempting to fulfill obligations with both countries at the same time. Students are maintaining their presence in university clubs, fulfilling professional obligations, and maintaining friendships to facilitate their reintegration into the home culture. While critics may argue that this distracts from a total immersion experience, changes in the nature of programs suggest that "total immersion" may no longer the goal of study abroad.

\section{Acculturative stress}

With regard to changes to the overall study abroad experience, evidence suggests that despite the introduction of Internet technology students still suffer from acculturative stress. Despite the fact that many students report low stress, feelings of hostility, and negative stereotyping of the target culture indicate otherwise. For example, when asked directly about his transition into German culture, Mark, a respondent from focus group three, reported, "it's been a really easy adjustment. I don't think I've had any problems." Nevertheless, when conversations turned to issues with German culture, Mark contributed,

For me, the bureaucracy is baffling here, and incredibly frustrating especially at the beginning, when you have to register in several different offices. You wait in line to get a number, then you finally get a number after 45 minutes, and then you wait for another two hours, to speak with someone who is usually quite rude (M3: Mark, undergraduate, taking courses in a full immersion program, abroad for one year).

Mark's quote regarding his heightened level of frustration in dealing with German protocol for university registration belies a heightened stress, and a rocky transition that he failed to report when asked directly about his level of stress. Mark later continues that a month into his stay in Berlin, he returned from shopping to find that the front wheel of his bike had been stolen. His story continues, "I had just gotten here. This was maybe a month after I had arrived and that just really sent me over the edge so I was on the U-bahn crying with a one-wheeled bike "(M3: Mark). When another student comforts Mark, saying that she, too, would have been likely to cry, Mark says in reference to his uncharacteristically strong response to the theft, "Yeah, I had just gotten here and I was kind of fragile." Mark's comments, that he had just arrived and was feeling "fragile" and "on edge," imply that he was dealing with his problems under added stress of the transition abroad.

Discussions of difficulties encountered abroad covered a range of 
topics from adjustment or transition, to everyday cultural and linguistic misunderstanding, to feelings of isolation. In complaining about German culture, however, a pattern emerged in which students were able to attribute minor cultural and linguistic misunderstandings to cultural differences, or to their own misstep, while more egregious culture clashes were attributed to Germans and German culture. Students told stories of the former with a mix of good humor, and mild embarrassment at their own cultural ignorance. For example, at the start of her sojourn abroad, Rebecca was surprised to find that stores were generally closed on Sunday. She says,

I didn't know everything was going to be closed on Sunday. I arrived on a Friday, and we had been traveling for 24 hours, so all we did was come [to the institute] pick up the key and go home. On Saturday, we walked around and didn't think to buy tons of food. I guess that if I had made a better effort [to meet people at the institute] on Friday, we could have eaten something other than crackers and pretzels on Sunday (R3: Rebecca, graduate student, taking courses at an English-speaking institute, abroad for 2 months).

In this instance, the threat from Rebecca's misstep was relatively minor, and the consequence was simply that Rebecca and her partner were not able to eat anything other than snacks on Sunday. The result is that Rebecca does not express frustration at store closures, but assigns responsibility to herself, saying, "if I had made more of an effort," the problem would likely not have arisen. From discussions of traffic, bicycle and pedestrian laws, to discussions of grocery store etiquette, in the event of minor, short-lived misunderstandings, students were likely to assign responsibility either to themselves, or to the intersecting of two different cultures. The result of assuming the role of "learner" was that students did not stereotype the culture and demonstrated an ability to reflect on the situation.

Yet small misunderstandings may begin to grate over time, particularly in the event that students find themselves explicitly corrected by members of the target culture. While host nationals are allowed, and encouraged, to be brokers of linguistic knowledge, students find it threatening when members of the host culture attempt to broker cultural knowledge in the form of behavior correction. One respondent reports,

I've noticed that people will try to teach me German words. If I say something wrong, they teach me the correct German way of saying it, so it's been a really easy adjustment. I don't think I've had any problems (Me3: Melissa). 
Conversely, when the knowledge being brokered through correction is cultural, students' reactions ranged from cold and indifferent, to harsh and accusatory. According to one respondent,

The other day, we were on the train, and a woman was calling us out for putting our bikes in a compartment that was allowed to have two bikes in it. Well there were exactly two bikes in the compartment so she was just talking at us and we just ignored her, and sat there not moving (G3: Grant).

Although it is unclear whether Grant was, in fact, breaking a rule - it should be noted that there are often stipulations to rules for bike travel on public transportation that Grant may not have been aware of. The cold reaction by Grant and his companion do not offer the woman a chance to explain, and demonstrate more frustration with the encounter than a willingness to learn from it.

Other encounters brought about much harsher reactions and reflections during complaint sessions. One respondent told the following story,

One of my friends came and she didn't bring my guest mother a present and [as a result, my host mother] was sort of like icy towards us all week. I was just like whatever. I don't really care. I'm like going home and I'm probably not going to talk to these guys again. My host mother confronted me after my friend left and was like, you know, 'next time you have a friend come they have to bring me a present. I expect it because I make you all this food' - she like toasts us bread - 'I made all this food, this is the least you could do.' She even still mentions it to me over and over and over again and I just find it to be so childish and so stupid (T4: Tom).

Rather than Tom looking upon this as a learning experience, it is clear from his reflections that he is externalizing the situation, assigning fault not to his misunderstanding of cultural expectations or even personal expectations, but to his host mother's "childish" and "stupid" demands, for appreciation for toasting bread.

The result is that student attitudes toward the larger culture can begin to reflect these stereotypical notions of rigidity and aloofness allowing students to save face by writing off the culture at large. Says one respondent,

I think it's true people do not have a problem to call you out if you're in any way violating a rule. However, if you are within the law but being a 
complete asshole - breaking things, throwing up, just generally being a problem, that's fine. You're not doing anything illegal. But if you want to cross the street, or if you walk on the grass when you're not allowed to, that is actually against the rules and they will call you out on it $(\mathrm{H} 3$ : Haley, graduate student, research assistant at an international research institute, abroad for two years).

When another student tells a story of being reprimanded for holding a door open, while she waited for her friend to add sugar to her coffee, Tom responds jokingly, "They were mad because in Germany you're supposed to be insensitive. I think you mixed up cultural sensitivity with cultural insensitivity (T4: Tom)."

The harsh language and insults used above, demonstrate hostility towards behavior correction and the brokering of cultural knowledge. Students assign cultural stereotypes circumventing not only the learning of the particular situation, but the openness to cultural difference required for future learning. This assignment of cultural stereotypes may also result in part from students' feelings of isolation from the both home and host cultures. Despite the advantage of cultural inlets through the Internet, students often reported feeling isolated from the target culture. Many students reported difficulties in adjustment, and making friends with Germans. Mark suggests that this may be a result of getting older,

I think the older you get, the harder it becomes to be the foreigner. I always compare this experience to the one I had in Argentina when I was 17. There I went clubbing three times a week, and within the first few months I had 80 numbers in my cell phone. Here at the university level everyone is kind of slowed down. They have girlfriends, even wives and husbands. So the older you get the more difficult it gets to penetrate the society and feel like you actually have good solid friendships (M3: Mark).

In fact, of the 21 students interviewed, only four reported significant friendships with members of the target culture: three students were placed with German roommates, and one student had a German girlfriend. Similarly, though the Internet has brought students into more regular contact with the home culture, Erin reports that the Internet does not make up for lack of a physical presence,

It's hard. I used to know my friends' schedules just because we lived together or because we were always so close. Now my best friend just 
got a job so she's never home before $11 \mathrm{pm}$ and by then it's the middle of the morning here and I'm not awake. Occasionally I try to call her cell phone with Skype but she's always in class so it's always really frustrating. I never know when we can actually talk (E3: Erin).

Many students expressed similar frustrations about leaving home during times of transition in their families.

Each stressor mentioned above creates a need for each of the hypothesized Internet uses. Transition difficulties lay the foundation for use of the Internet as a transition device. In response to feelings of isolation from the host culture, and feelings of cultural ineptitude students may find themselves searching for informational support, as well as resources for gaining access to the target culture through cultural events. Finally, fears of isolation from the home culture - and of being left behind - may be calmed by access to online resources which help students maintain personal and professional obligations in the home country, though they are physically located abroad.

\section{Discussion}

The purpose of the present study was to examine changes to the traditional study abroad experience given changing notions of transition brought about by widespread use of advanced communication technologies. Using data collected from in-depth focus group interviews with 21 American students studying abroad in Germany over 200 pages of text were generated from which three themes emerged. Data suggests that students are using the Internet to: 1) access emotional and embedded support to facilitate the transition into the new culture; 2) quickly and efficiently establish daily routines in the target culture; and 3) fulfill professional and social obligations back in the United States while abroad. Nevertheless, the results indicate that students are still suffering from acculturative stress, and suggest the possibility that the Internet may risk transforming the traditional notion of cultural exploration, into one of cultural consumerism.

Implications for students and short-term migrants in general are largely positive. Focus group interview data demonstrated that the Internet is an effective way of seeking out emotional support from the home country that can help migrants to navigate a difficult transition abroad. The Internet provided a medium through which to maintain important relationships in the home culture, while also providing a continuity in behavior expectations, language and identity through embedded social support networks which students were able to carry abroad with them. Furthermore, students reported using 
the Internet to connect with co-nationals, providing a network of support comprised of other foreigners likely to understand the difficulties of living abroad. Often students were able to find important information online in their native language, and where such information was not available in English, students were able to find resources to help them interpret the target language either completely such as with programs like Google Translate, or in part through online dictionaries.

Support seeking online was not limited to providing a link to the home culture and language, however. Through the Internet, students were able to find inlets into the target culture, and form relationships with host nationals, as well. Students reported using the Internet to find cultural activities based on their interests, thereby expanding possibilities for social interaction and the formation of cross-cultural friendships. Students are no longer required to make do with everyday encounters in order to develop superficial linguistic and cultural proficiency. Seeking out cultural events has the potential to provide a solid foundation for stronger friendships based on a common interest and puts students in touch with the realia which constitutes the experiential learning in study abroad. Students are exhibiting this same agency in the establishment of their daily lives abroad. Internet search and mapping programs are allowing students to exercise independence in everything from locating apartments, to locating corner grocery stores, fitness centers and shopping malls. Study abroad is responsible for providing students a means to study at a foreign institution through a pre-established network of support. Today, the Internet similarly reduces the risks of living abroad by providing the same pre-established network of support for everything outside of the university.

Nevertheless, the verdict on Internet use is complicated given the dual goal of alleviating stress, while also creating an environment conducive to learning. The result is a tale that is far more cautionary. The lengthening of the initial transition period suggests less time actively engaged with the target culture, while attending to responsibilities back in the home culture during study abroad prevents full immersion and lengthens the transition out of the host culture. Linda Stone, a blogger for the Huffington Post, comments on the constant straddling of cyber and real space saying that students are engaging in a "continuous partial attention." According to Stone, continuous partial attention refers to the desire to remain a constant active node. As a result, engagement in any one activity is limited due to constant attending to several other, potentially more interesting activities. Several programs have exacerbated this problem by shortening the amount of time students are spending abroad making for very superficial cultural engagement, and leaving students and administrators equally dissatisfied with the results. 
The Internet also risks changing the nature of study abroad from process to product. When transactions could be conducted online, students were likely to see the face-to-face counterpart transactions as pointless. In other words, students asked why they would visit a ticket agent in a train station, when the same transaction could be accomplished in a fraction of the time online. The problem with such logic is that the goal is not the train ticket. Rather, the goal is the cultural and language skill set exercised in the purchase of the ticket. Data show that students' interest in speed and efficiency have changed the focus from long-term goals like cultural learning, to short-term goals like ticket purchases. It is the shift toward more cultural than functional goals that distinguishes study abroad from tourism. This switch in focus has enabled students to rapidly and efficiently integrate into the target culture. Unfortunately, where it may now take only several days to learn how to physically navigate a city, students lack sufficient cultural knowledge to set up a life that reflects the values of the culture in which they are living. Students therefore set up the life abroad that they had envisioned back in the United States and that reflect American values.

The establishment of a daily routine that fails to account for the values of the host culture may be a symptom of a larger problem. It is possible that the continuous engagement with the home culture through the Internet is "normalizing" American behavior such that students' frame of reference never changes. Part of the study abroad experience is students' shedding of their ethnocentric worldview, in order to adopt a more international perspective. If students continue to create an insular world in which America is the norm and all other countries constitute a deviation, then students' worldview is unlikely to change. Evidence of this ethnocentrism can be seen in the results section on acculturative stress where some students demonstrated an attitude of entitlement and some exaggerated notions of cultural difference, both of which stand in direct opposition to the goals of study abroad.

Where normative theories of intercultural adjustment are concerned, the present study offers some new and exciting insights. Evidence suggests that the Internet is smoothing out previous abrupt transitions into and out of the target culture, indicating that it may no longer be relevant to refer to a culture "shock." Students are no longer affronted by the host culture, but able to choose their degree of involvement, etreating to a more familiar identity affirming embedded or socio-emotional support when cultural encounters become too difficult. Berry's model of acculturation strategies / acculturation attitudes may also have to be reanalyzed given such ready access to members of the home culture via the Internet. It may no longer be relevant to discuss an "abandonment" of the home culture in any but the most exceptional of 
cases - as immigrants and sojourners have unrestricted access to co-nationals online. Finally, acculturative stress in general may undergo a shift from entirely undesirable, to occasionally desirable. If students are failing to encounter stress, or are fleeing to the safety of online interaction when faced with stress, it may indicate that students are seeking justification for culturally insensitive behaviors. American behavior becomes the standard, and students fail to adapt to behavioral expectations within the target culture, leading to a decrease in cultural learning. Rather than buffering students from stressful encounters, the next step for administrators may be to encourage students to confront stresses, in order to adapt and learn.

\section{Conclusion}

Internet communication has changed the traditional study abroad experience by providing students with additional options: students choose where, when and through whom to seek support; but also where and when to engage in the target culture. Further research on the topic of Internet mediated social support during study abroad should aim to quantify the trade-off between hours spent online and hours spent actively engaging with members of the target culture. Future research should also consider the use of quantitative data to examine the link between hours spent online and stress level during study abroad by considering whether the Internet represents active or avoidance coping (Roth, S., \& Cohen, L.J., 1986). Finally, longitudinal data would help uncover an Internet use trajectory to determine the extent to which Internet use follows a regular pattern, and help administrators to spot deviations that may indicate abnormal Internet dependence.

\section{References}

Adler, P. (1975). The Transitional Experience: An alternative view of Culture

Shock. Journal of Humanistic Psychology, 15(4), 13-23.

Baym, N.K., Zhang, Y.B., \& Lin, M. (2004). Social interactions across media.

New Media \& Society, 6, 299-318.

Berry, J. (1997). Immigration, Acculturation, and Adaptation. Applied

Psychology: An International Review, 46(1), 5-68.

Bolger, N., Zuckerman, A., \& Kessier, R. (2000). Invisible support and

adjustment to stress. Journal of Personality and Social Psychology, 79,

953-961. 
Burke, M., Kraut, R., and Williams, D. (2010). Social use of computer-mediated communication by adults on the autism spectrum. ACM CSCW 2010:

Conference on Computer-Supported Cooperative Work, 425-434.

Church, A. (1982). Sojourner Adjustment. Psychological Bulletin, 91, 540-572.

Cobb, S. (1976). Social support as a moderator of life stress. Psychosomatic Medicine, 38(5), 300-314.

Cohen, S. \& Wills, T. (1985). Stress, Social Support, and the Buffering Hypothesis. Psychological Bulletin, 98(2), 310-357.

Dimmick, J., Ramirez, J., Wang, T., \& Lin, S. (2007). 'Extending society': the role of personal networks and gratification-utilities in the use of interactive communication media. New Media Society, 9, 795-810.

Gorka, B. \& Niesenbaum, R. (2001). Beyond the Language Requrirement: Interdisciplinary Short-Term Study-Abroad Programs in Spanish. Hispania, 84 (1), 100-109.

Gullahorn, J. T., \& Gullahorn, J. E. (1963). An Extension of the U-Curve Hypothesis. Journal of Social Issues, 19(3), 33-47.

Hammer, M. (1981). Social Supports, Social Networks, and Schizophrenia. Schizophrenia Bulletin, 7(1), 45-57.

Hampton, K., \& Wellman, B. (2003). Neighboring in Netville: How the Internet Supports Community and Social Capital in a Wired Suburb. City \& Community, 2(4), 277-311.

Kraut, R., M. Patterson, V. Lundmark, S. Kiesler, T. Mukhopadhyay and W. Scherlis (1998) 'Internet Paradox: a Social Technology that Reduces Social Involvement and Psychological Well-being?’, American Psychologist 53(9): 1017-31.

Leung, L. (2007). Stressful Life Events, Motives for Internet Use, and Social Support Among Digital Kids. Cyberpsychology and Behavior, 10, 204-214. Lysgaard, S. (1955). Adjustment in a Foreign Society: Norwegian Fulbright Grantees Visiting the United States. International Social Science Bulletin, 7, 45-51.

Malik, S. \& Coulson, N. (2008). Computer mediated infertility supportgroups: An exploratory study of online experiences. Patient Education and Counseling, 105-113.

McKenna, K. Y., \& Green, A. S. (2002). Virtual Group Dynamics. Group Dynamics: Theory, Research, and Practice. Special Issue: Groups and Internet, 6(1), 116-127.

McKenna, K. Y., Green, A. S., \& Gleason, M. E. (2002). Relationship formation on the Internet: What's the big attraction? Journal of Social Issues. Special Issue: Consequences of the Internet for self and society: Is social life being transformed? 58(1), 9-31. 
McKinlay, N. J., Pattison, M., \& Gross, H. (1996). An Exploratory Investigation of the Effects of a Cultural Orientation Programme on the Psychological Well-Being of International University Students. Higher Education, 31(3), 379- 395.

Oberg, K. (1960). Culture shock: adjustment to new cultural environments. Practical Anthropology, 7, 177-182.

Papacharissi, Z., \& Rubin, A. (2000). Predictors of Internet Use. Journal of Broadcasting and Electronic Media, 44 (2), 175-196.

Putnam, D. E. (2000). Initiation and maintenance of online sexual compulsivity: Implications for assessment and treatment. CyberPsychology \& Behavior, 3(4), 553-563.

Raake, J., \& Bonds-Raake, J. (2008). MySpace and Facebook: Applying the Uses and Gratifications Theory to Exploring Friend-Networking Sites. CyberPsychology \& Behavior, 11 (2), 169-174.

Robinson, J. P., Kestnbaum, M., Neustadtl, A., \& Alvarez, A. (2000). Mass media use and social life among Internet users. Social Science Computer Review. Special Issue: Survey and statistical computing in new millennium, 18(4), 490-501.

Roth, S., \& Cohen, L.J. (1986). Approach, Avoidance, and Coping with Stress. American Psychologist, 813-819.

Shaw, L.H., \& Grant, L.M. (2002). In Defense of the Internet: The relationship between Internet Communication and Depression, Loneliness, Self-esteem and Perceived Social Support. Cyberpsychology, 5(2), 157-171.

Stone, L. (2009). Continuous Partial Attention. Retrieved on February 21, 2010 from http://lindastone.net/qa/continuous-partial-attention/.

Subrahmanyam, K., Reich, S., Waechter, N. \& Espinoza, G. (2008). Online and offline social networks: use of social networking sites by emerging adults. Journal of Applied Developmental Psychology, 29, 420-433.

Thoits, P.A. (1985). Social Support and Psychological Well-Being: Theoretical Possibilities. In Sarason, I.G. \& Sarason, B.R. (Eds.), Social Support: Theory, Research, and Applications. Dordrecht, The Netherlands: Martinus Nijhof.

Turner, R. J., Frankel, B.G., \& Levin, D.M. (1983). Social support, Conceptualization, measurement, and implications for mental health. Research in Community and Mental Health, 3, 67-111.

Ward, C., \& Kennedy, A. (1994). Acculturation strategies, psychological adjustment, and sociocultural competence during cross-cultural transitions. International Journal of Intercultural Relations, 18 (3), 329-343. 
Wethington, E. \& Kessler, R. (1986). Perceived Support, Received Support and Adjustment to Stressful Life Events. Journal of Health and Social Behavior, 27(1), 78-89. 